\title{
Effects of microRNAs in hypertension disease
}

\author{
Nuray Altıntaş॰, Onur Tonk $\odot$, Özge Sarıca Yılmaz $\odot$ \\ Department of Medical Biology, Manisa Celal Bayar University, Faculty of Medicine, Manisa, Turkey
}

\begin{abstract}
Objectives: Hypertension is a cardiovascular disease which is a very common hemodynamic syndrome, and it has different prevalence in different regions as it is common all over the world. In recent studies, it is known that microRNAs (miRNAs) play an important role in hypertension disease and that miRNA expressions are regulated by epigenetic mechanisms. There are also studies proving that microRNAs are new therapeutic targets for pulmonary arterial hypertension, and miRNAs can participate in the pathophysiology of hypertension in many ways and it can be used as a biomarker for hypertension disease. It is thought that miRNAs can be effective in the diagnosis and treatment of hypertension and further studies are needed. Recently, the relationship between miRNAs and hypoxia has also been focused on and has been taken into account in studies. In this review, we aimed to present the effects of miRNAs on hypertensive disease and current approaches. Finally, with gene targeting studies, we think that miRNAs, which can be biomarkers and molecular agents, will hold promise in preventing the progression of hypertension in the future, and we hope that they can create ideas for future studies.
\end{abstract}

Keywords: miRNA, hypertension, epigenetic

$\mathrm{H}$ ypertension is a common cardiovascular disease that occurs with high blood pressure. Hypertension disease causes harmful complications and poses a risk for diseases such as stroke, coronary artery disease, heart failure and chronic kidney failure $[1,2]$. In addition, hypertension (HTN) is a disease that continues to be quite common around the world. Essential hypertension (EH) is a highly complex and polygenic condition, and in addition epigenetic modifications are very important in the development of EH. Known for genetic and environmental systems involved in determining the risk of EH Genetic and environmental systems are known involved in determining the risk of EH (Fig. 1) [3].

Nitric oxide acts as an anti-inflammatory agent and prevents leukocyte adhesion. This prevents vascular inflammation and causes vasodilation, resulting in hypertension [4]. Pulmonary hypertension ( $\mathrm{PH})$ is a lung disease that occurs when the pulmonary artery pressure reaches a quarter of the blood pressure in the whole organism. Recent studies focus on the importance of microRNAs (miRNAs) and are underway in many recent studies on the effects of miRNAs in human disease [5]. miRNAs are non-coding RNAs of about 21-25 bp long and play an important role in various biological processes such as differentiation, proliferation, migration, and apoptosis on hypertension diseases as with all diseases (Fig. 2) [2, 5, 6, 7].

The formation of miRNA is based on the occurrence of a number of processes in the cell, nucleus and cytoplasm. The first miRNA synthesized is called primiRNA and is about 700 bases long. This primary miRNA is synthesized by RNA polymerase II. It has a cap ( 5 'cap) and a poly-A tail. After the pri-miRNA 


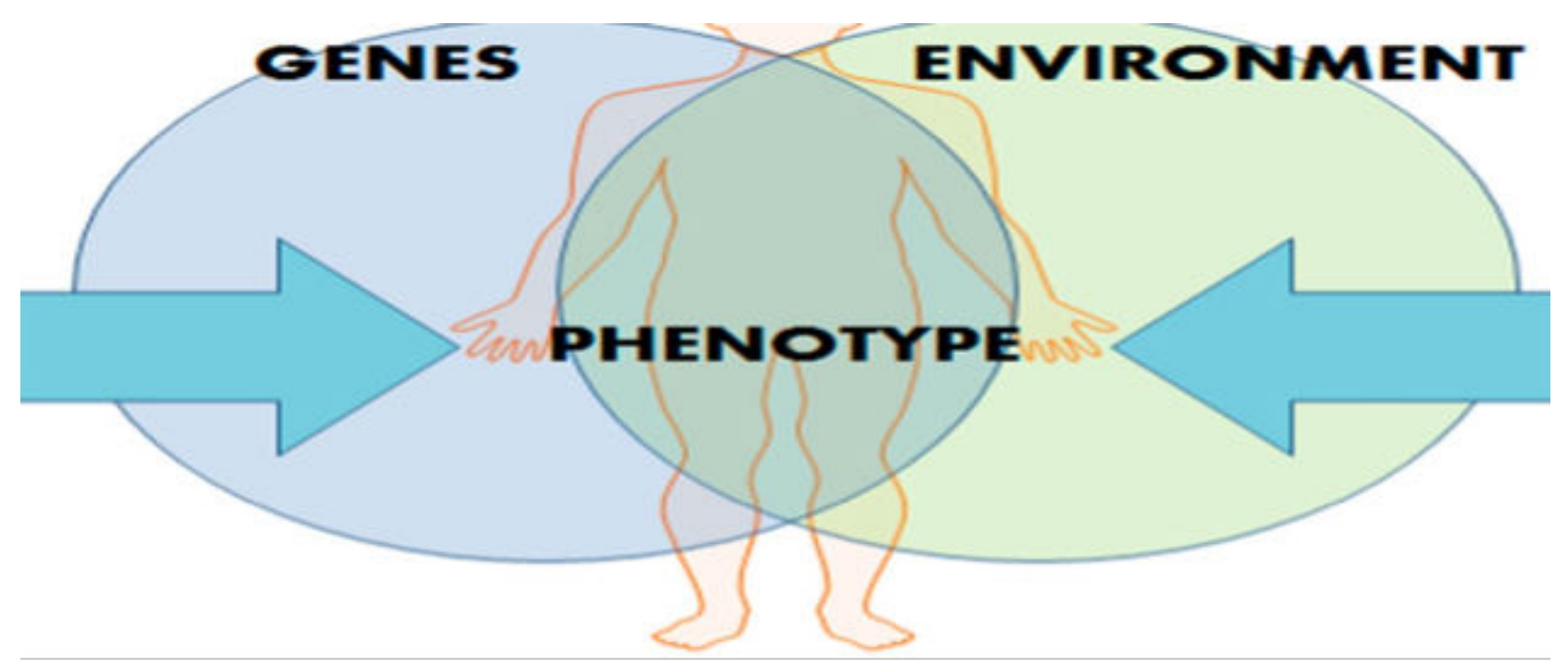

Fig. 1. Effects on phenotype. Genetic and environmental systems are effective in the development of essential hypertension $[3]$.

is cleaved by the Dorsha enzyme, a precursor miRNA called pre-miRNA is formed and is about 70 bases long. The precursor miRNA is then transported through nuclear pores to the cytoplasm. This transport takes place with the exportin-5 protein. The stem ring of pre-miRNAs is then cut with the Dicer enzyme, resulting in two complementary short RNA molecules. The stable, i.e. mature miRNA binds to the RNA-derived silencing complex (RISC) and performs its function. Lost when other RNA is broken down (Fig. 3) [6, $8,9]$.

Non-coding RNAs are divided into two; small non-coding RNAs and long non-coding RNAs. Long non-coding RNAs are regulated by miRNAs. In addition, the main functions of miRNAs include their role in gene regulation by binding to the RNA-1nduced silencing complex (RISC). In the regulatory complex that has formed, Argounate functions as the main protein. Small RNAs are found in the active site of the Argounate protein, miRNA and mRNA forms the triple complex. Causes a pressure on gene expression through mRNA cleavage or translational suppression (Fig. 4) [10, 11].

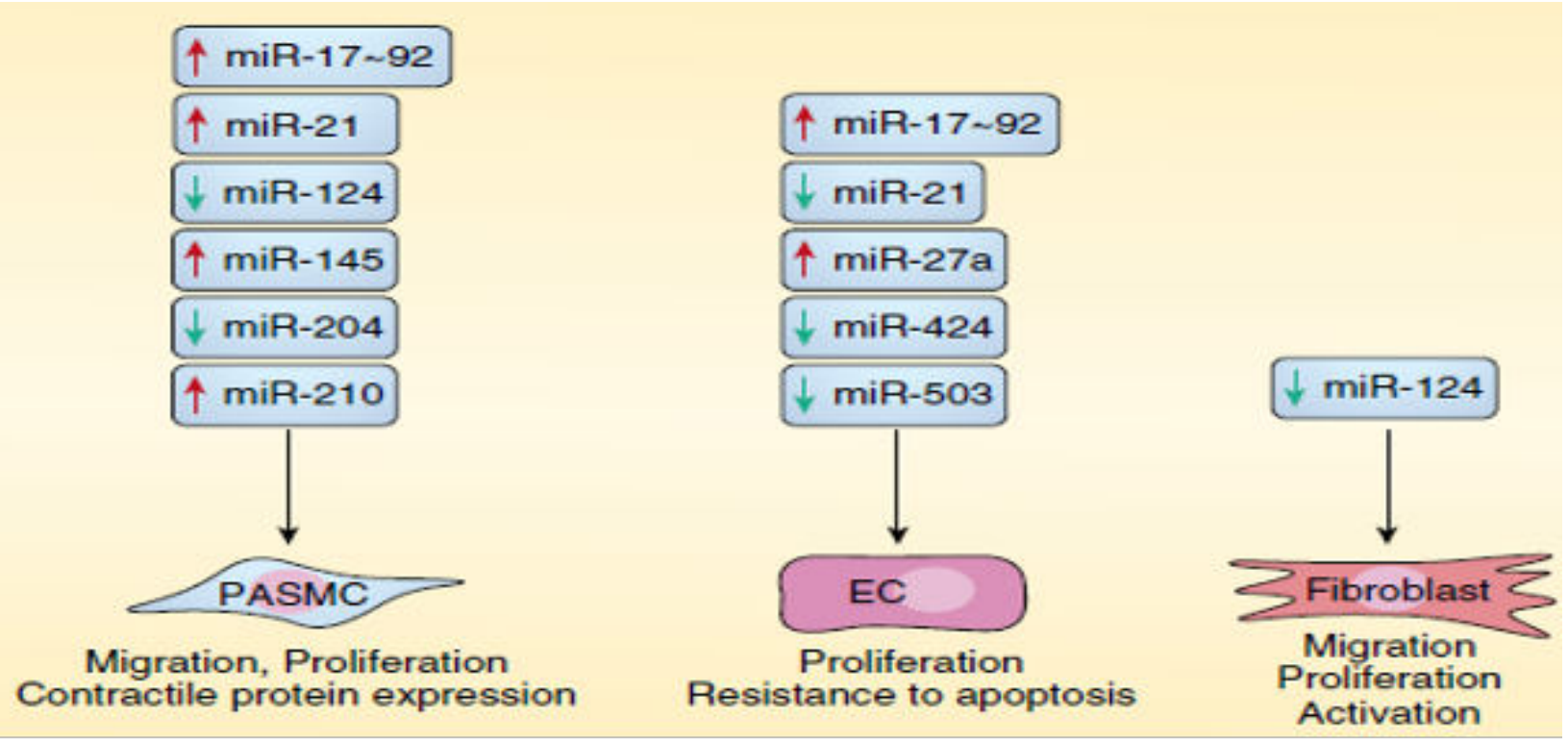

Fig. 2. Schematic diagram showing microRNAs contributing to the pathogenesis of pulmonary arterial hypertension [7] 


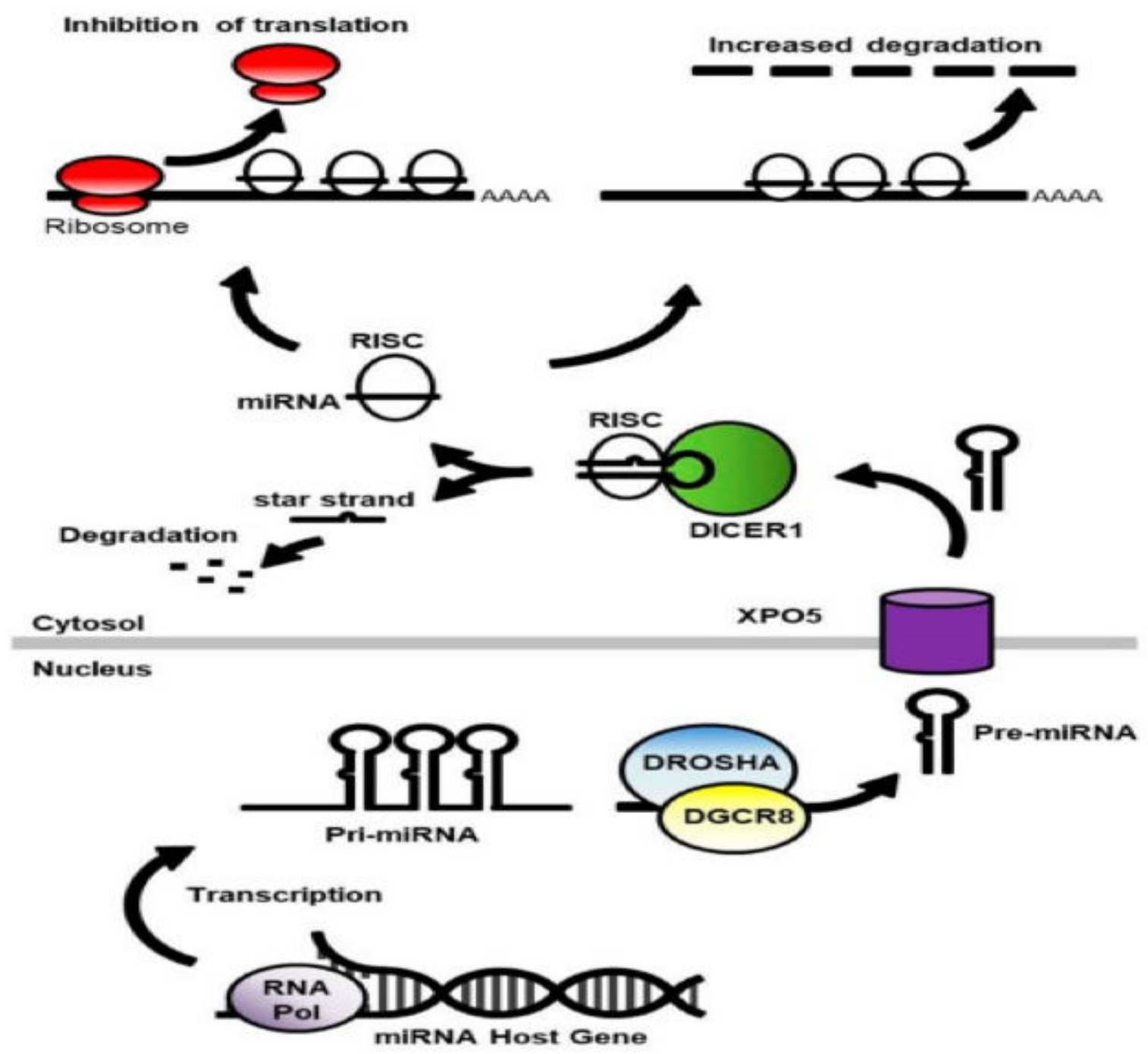

Fig. 3. Schematic view of microRNA (miRNA) processing and function [9].

Epigenetic Mechanisms and Its Effect on Hypertension Disease

miRNAs play an important role as epigenetic modulators by interacting with enzymes involved in epigenetic mechanisms such as DNA methyltransferase (DMTs), histone deacetylase (HDACs), and histone methyltransferases (EZHs). In addition, epigenetic mechanisms such as DNA methylation, RNA modification, and histone modification regulate the expression of miRNAs. With miRNAs, epigenetically related cell proliferation creates a new mechanism in regulating cell processes such as apoptosis and differentiation. Additionally, miRNAs can affect the expression of the epigenetic mechanism by targeting enzymes that are associated with epigenetics. MiRNAs are increasingly important in epigenetic expressions, such as; DNA methylation, RNA modification and histone modification (Fig. 5) [12, 13].

Epigenetic mechanisms play an important role in expressing the inherited characteristics that contribute to the pathogenesis of many cardiovascular diseases and in the transmission of risk factors for hypoxia-sensitive pulmonary arterial hypertension (PAH) from generation to generation (Fig. 6) [14, 15].

The Prevalence of Hypertension Disease in the World and in Turkey

There are important differences in the prevalence of HTN in the USA; Hypertension is seen in $43 \%$ of African American women, $45.7 \%$ of men, 33.9\% of white men and $31.3 \%$ of women. In a healthy 45 -yearold African American, the risk of developing HTN is 92.7\%, compared with $92.4 \%$ in Hispanic populations. On the other hand, the risk of developing HTN among 


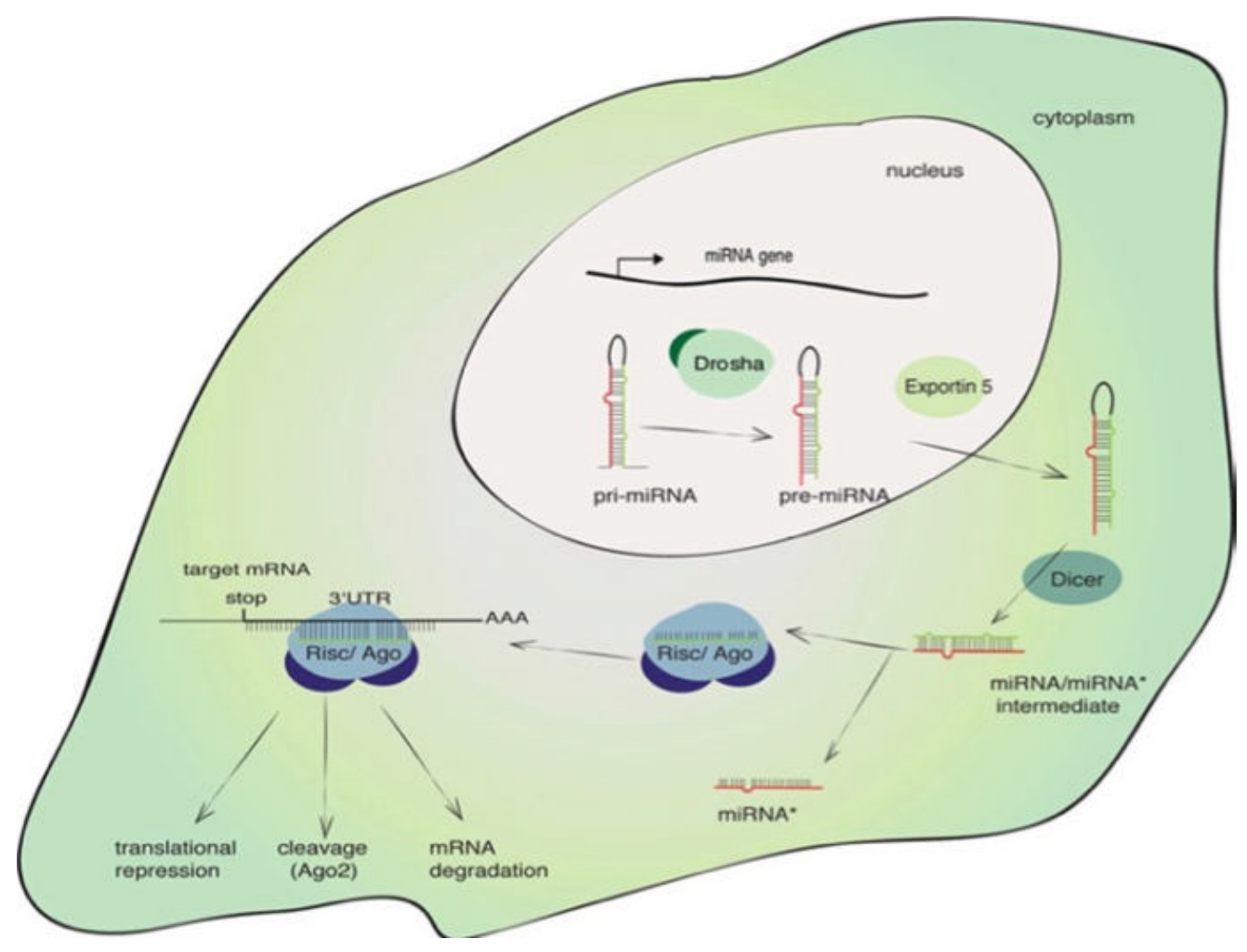

Fig. 4. Schematic overview of the miRNA pathway [10].

Caucasians is relatively low (up to $86 \%$ ) and even lower in Asian populations (84.1\%) [4]. Hypertension affects approximately $25 \%$ of the adult population worldwide, and it is estimated that the number of adults with hypertension will increase by approximately $60 \%$ in the coming years. In the United States, hypertension affected $30 \%$ of the population in 2015 . According to the " 2017 High Blood Pressure Clinical Practice Guidelines", the prevalence of hypertension has increased significantly (46 to $32 \%$ ) among US adults [2]. Hypertension is a widespread public health problem in our country as well as all over the world. According to the "Turkish Hypertension Prevalence Study", the prevalence of hypertension in adults (18 years and older) is $31.8 \%$ (males; $27.5 \%$, females; $36.1 \%$ ). Blood pressure control in all hypertensives is $8 \%$, and it is $20.7 \%$ in patients who are aware of high blood pressure and who are treated [16].

\section{miRNAs Related to Hypertension Disease}

According to studies conducted in hypertensive patients, a significant increase in miR-21 expression levels compared to healthy control group was observed. The mechanism of miR-21 increased in target organ damage is unknown. Moreover, miR-21 is a molecule involved in the regulation of vascular remodeling during EH [2]. In recent studies, it has been reported that with a decrease in miR-21 expression levels, it has a role in regulating the Programmed cell death protein 4 (PDCD4) and Activator protein 1 (AP1) signaling pathway [17].

miRNAs are expressed differently in many diseases, including pulmonary hypertension (Fig. 2). One study reported that miR-204 is involved in reducing blood pressure $[7,18]$. In one study, miR-214 was known to downregulate Phosphatase and tensin homolog (PTEN) and suppress apoptosis and promote the proliferation of Pulmonary Artery Smooth Muscle Cells (PASMCs). Thereupon, in the same study, it was found that miR-214 targets PTEN. As a result, miR214 is thought to be a promising diagnostic tool for pulmonary hypertension (PH) [5]. Also In recent studies, it has been stated that miR-214 plays a role in controlling perivascular fibrosis [19].

In the studies conducted, it was observed that hsamiR-145 expression increased significantly in atherosclerotic plaques taken from hypertensive patients compared to the health control group. It has been noted that hsa-miR-145 and hsa-miR-122 are associated with the development of hypertension. Also hsa- 


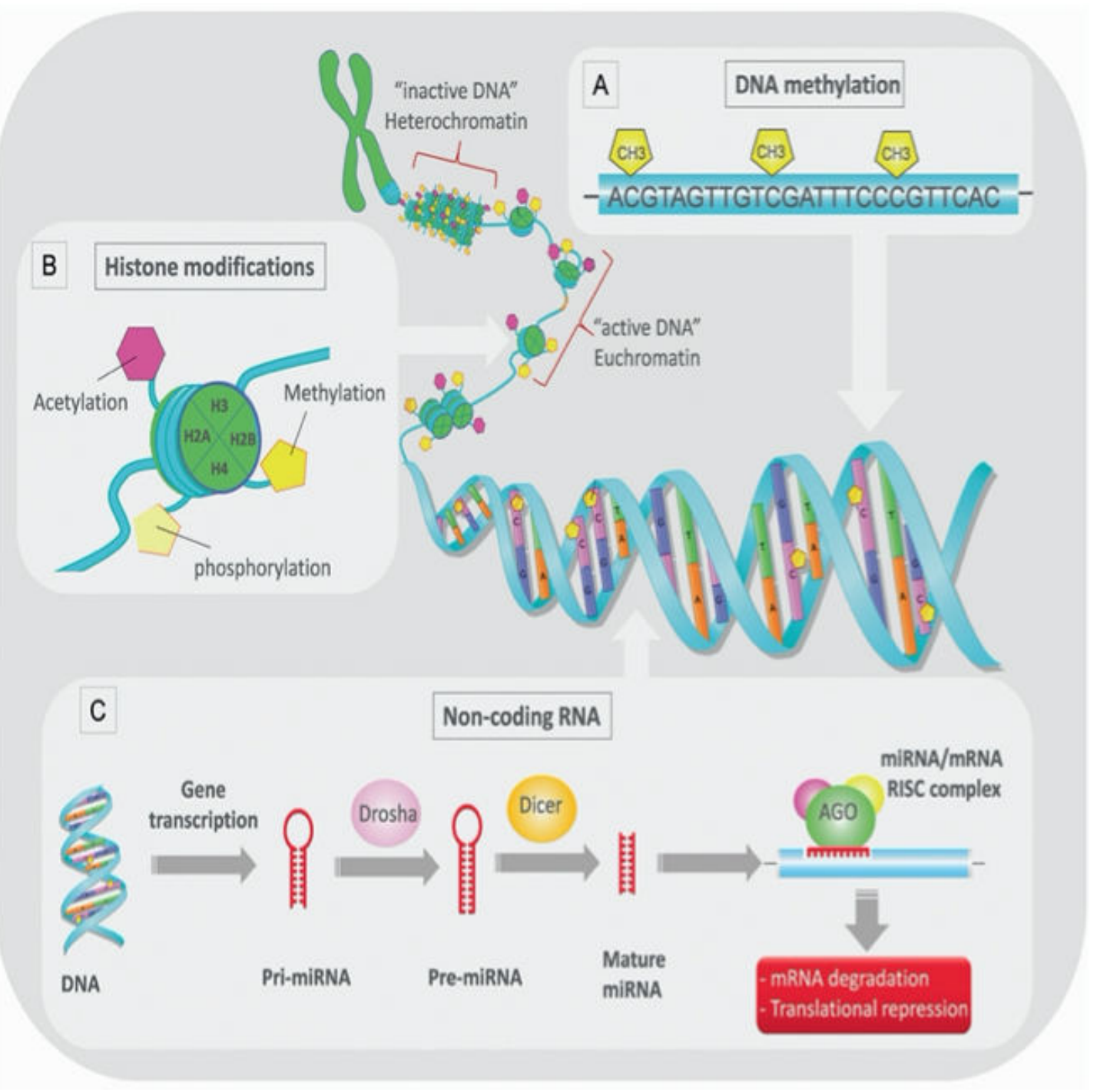

Fig. 5. Epigenetic modifications of miRNA in a mammalian system [12].

miR-21 is thought to be suitable for miRNA-based therapeutics as it plays a role in lowering blood pressure [20]. miR-126a-5p plays a role in the hypoxiamediated endothelial migration of neonatal pulmonary hypertension [2]. In another study, it was concluded that miR-17 regulates the Th1 reaction and the production of interleukin-10. Moreover, miR-15 expression was reported to increase the induction of T cells [21]. In a study, it was reported that miR-223 expression levels decreased in the lungs, arteries and smooth muscle cells of hypertensive patients and this decrease was regulated by HIF-1 alpha activity. As a result of this regulation, it was concluded that PARP-1 activity was upregulated and had a positive effect on endothelial dysfunction [22]. Another study concluded that miR-223-3p targets ITGB3 and i1k of PAH [26]. In miR-1 essential hypertensive patients and pre-eclamp-
S1as are upregulated in peripheral blood mononuclear cells [24].

miRNA is known to play an important role in the development of hypertension as well as preventive and reparative therapeutics for hypertension. Vascular smooth cells (VSMC) enable the formation of the medial layer of the vessels. miRNAs play an important role in VSMC development, phenotype and transcriptional regulation [4].

miR-145 is known to play an important role in the development of the cardiovascular system as a regulator. It has also been reported that mir-145 is required for VSMC differentiation [1]. It is also known that miR-9 and miR-126 are closely related to $\mathrm{EH}$ in humans and that these miRNAs are associated with the prognosis of target organ damage in hypertensive patients [4]. 


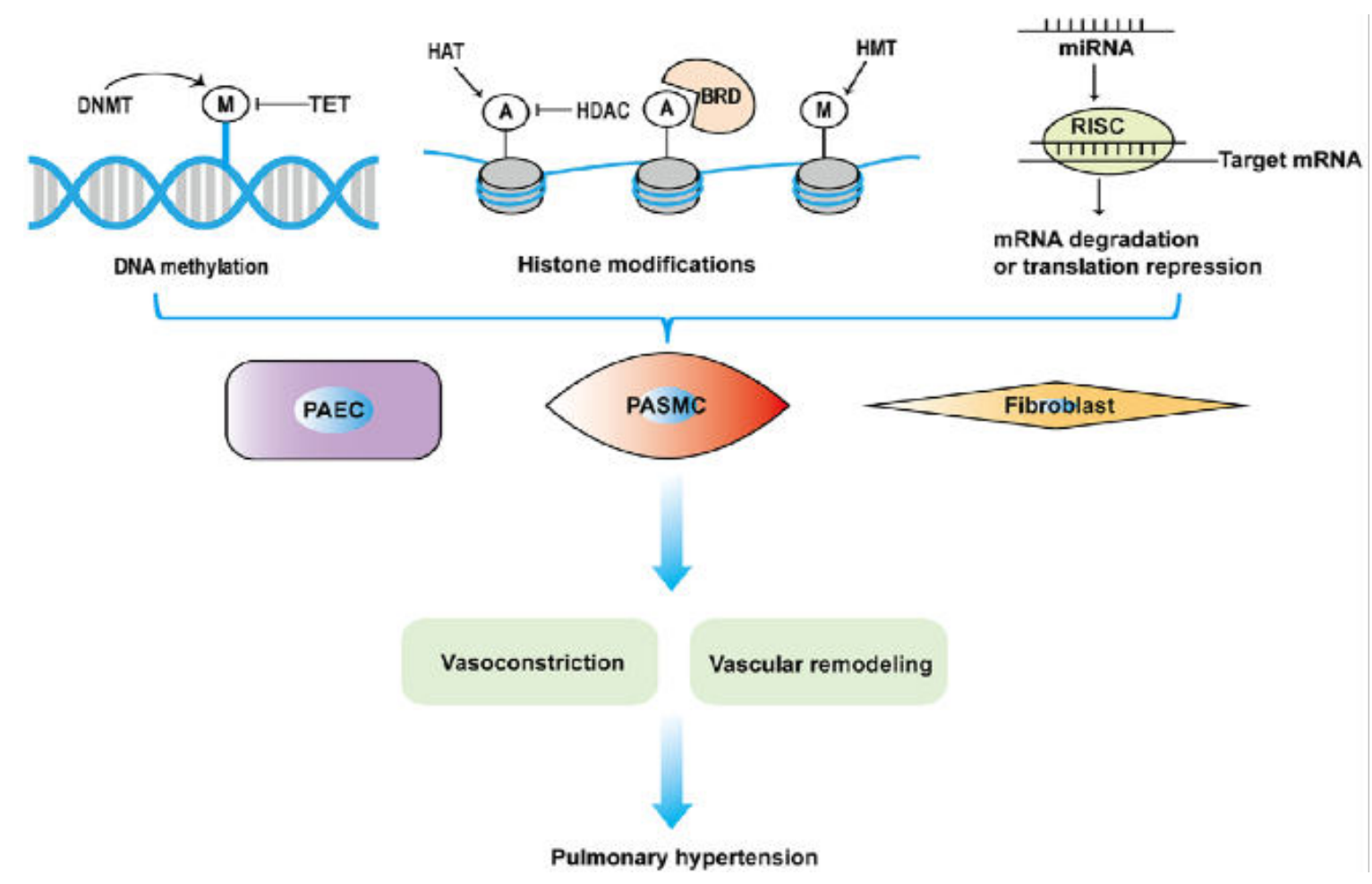

Fig. 4. Schematic overview of the miRNA pathway [10].

Endothelial cells contribute to the pathogenesis of hypertension by secreting many substances. One of them is nitric oxide. Nitric oxide is involved in maintaining normal blood pressure. It is known that there is a relationship between impaired nitric oxide activity in hypertension and increased arterial tone, but its mechanism is still not understood. It acts as a biomarker in the diagnosis of many diseases such as cardiovascular diseases. miR-155 can be useful in preventing the development of hypertension by regulating the endothelial nitric oxide synthase (eNOs) enzyme [25]. On the other hand, in one study, it was concluded that miR-155- $5 \mathrm{p}$ caused vasorelaxation impairment by down-regulation of eNOS found in endothelial cells [26]. It has been reported that miR-100 targets the rs6186923 polymorphic region of the TRB3 gene and consequently affects hypertension and left ventricular hypertrophy. However, the researchers argue that rs6186923 should be verified with miR-100 western blot and evaluated further in future studies [27].

It is known that miR-140-5p expression is decreased in both PAH patients and rat monocrotolin-induced PAH models. SMURF1 and DUMT have been found to be direct target genes of miR-140-5p in pul- monary artery smooth muscle cells (PASMCs) and play a role in the pathogenesis of PAH. In the same study, it was found that the target genes of miR-140$5 \mathrm{p}$ contributed to PAH-related biological processes such as biological regulation, metabolic process, cell communication, and response to chemical stimuli [28]. It is known that the combination of miR-199a$3 p$, miR-208a-3p, miR-122-5p and miR 223-3p is a marker for the diagnosis of hypertension and that miRNA dysregulation increases the risk of hypertension [29]. A study from exosomes concluded that hsamiR-210 is secreted through exosomes that play a role in the pathomechanism of the disease [30].

Li et al. [31] reported that miR-124 is down-regulated in cells exposed to hypoxia. It was observed that the level of mRNA expression normalized with miR124 was lower in PASMCs originating from PAH and COPD compared to the control group, and it was concluded that miR-124 may play a role in the pathogenesis of PAH in COPD patients. In the same study, PASMCs were subjected to hypoxia, and miR-124 was observed to be significantly downregulated, and GRB2 mRNA expression was found to be significantly upregulated in cells exposed to hypoxia relative to cells exposed to normoxia [31]. 
Hypertension is a multifactorial cardiovascular disease. Stroke is an important risk factor for the development of coronary artery disease, heart factor, and chronic kidney factor $[1,2]$. miRNA are small noncoding RNAs that are approximately 16-25 bp long. There is a relationship between miRNAs and hypertension in several ways. It is known that miRNAs play an important role in the pathogenesis of hypertension. Recently, scientists have focused on miRNA and hypertension relationships. Studies by many scientists have shown that expression levels of miRNAs are involved in different biological processes $[2,5]$. There is also a relationship between miRNAs and hypoxia. In hypertensive patients, miR-21 can be used as a new therapeutic target against the development of atherosclerosis, and studies have also found that miR-214 is a novel therapeutic target as it is a promising diagnostic tool [5].

It has also been reported that many miRNAs such as miR-210, miR-124, miR-204 and miR-138 regulate SMC gene expression in PAH due to hypoxia [32]. Also, as a result of recent studies, miR 223-3p, miR$27 \mathrm{a}, \mathrm{miR}-150$ could be new therapeutic targets for PAH $[23,26]$. In addition, it was concluded that NO, which is associated with hypertension, contributes to the prevention of hypertension [4]. Finally, the regulatory effect of miRNAs on epigenetic expression has been more and more known in recent years [1]. miRNAs also target epigenetic-related enzymes and the expression of epigenetic mechanism components [13]. miRNAs can be used as biomarkers for hypertension [1].

\section{CONCLUSION}

As a result, miRNA plays a crucial role in the development of HTN and has the potential to target these miRNAs as preventive and restorative therapy for HTN. The relationship, effects and importance of miRNAs on hypertension are discussed in this review. In the future, miRNAs are thought to be a solution to diseases such as hypertension and may be effective in the diagnosis and treatment of diseases.

\section{Conflict of interest}

The authors disclosed no conflict of interest during the preparation or publication of this manuscript.

\section{Financing}

The authors disclosed that they did not receive any grant during the conduction or writing of this study.

\section{Authors' Contribution}

Study Conception: NA; Study Design: NA, OT; Supervision: NA, ÖSY; Literature Review: NA, OT; Manuscript Preparation: NA, OT and Critical Review: NA, ÖSY.

\section{REFERENCES}

1. Wang Y, Jin L. miRNA-145 is associated with spontaneous hypertension by targeting SLC7A1. Exp Ther Med 2018;15:54852.

2. Li X, Wei Y, Wang Z. microRNA-21 and hypertension. Hypertens Res 2018;41:649-61.

3. Wise IA, Charchar FJ. Epigenetic modifications in essential hypertension. Int J Mol Sci 2016;17:451.

4. Jalnapurkar S, Mangaonkar A, Mondal A, Burke J, Fulzele S, Kolhe R. MicroRNAs: as a novel potential tool for diagnosis, prognosis, and therapeutic agents in hypertension. Hypertens Cardiol 2015;1:14-22.

5. Liu H, Yin T, Yan W, Si R, Wang B, Chen M, et al. Dysregulation of microRNA-214 and PTEN contributes to the pathogenesis of hypoxic pulmonary hypertension. Int J Chron Obstruct Pulmon Dis 2017;12:1781-91.

6. Güzelgül F, Aksoy K. A gene expression regulator: miRNA. Arşiv Kaynak Tarama Dergisi 2015;24:472-93.

7. Zhou G, Chen T, Raj JU. MicroRNAs in pulmonary arterial hypertension. Am J Respir Cell Mol Biol 2015;52:139-51.

8. Shomron N, Levy C. MicroRNA-biogenesis and pre-mRNA splicing crosstalk. J Biomed Biotechnol 2009;2009:594678.

9. Gibbons A, Udawela M, Dean B. Non-coding RNA as novel players in the pathophysiology of schizophrenia. Noncoding RNA 2018;4:11.

10. Beitzinger M, Meister G. Experimental identification of microRNA targets by immunoprecipitation of argonaute protein complexes. In: Dalmay T (eds). MicroRNAs in Development. Methods in Molecular Biology (Methods and Protocols). Humana Press. 2011.

11. Frydrych Capelari É, da Fonseca GC, Guzman F, Margis R. Circular and micro RNAs from arabidopsis thaliana flowers are simultaneously isolated from AGO-IP libraries. Plants (Basel) 2019;8:302.

12. Arif M, Sadayappan S, Becker RC, Martin LJ, Urbina EM. Epigenetic modification: a regulatory mechanism in essential hypertension. Hypertens Res 2019;42:1099-113.

13. Yao Q, Chen Y, Zhou X. The roles of microRNAs in epigenetic regulation. Curr Opin Chem Biol 2019;51:11-7.

14. Cheng X, Wang Y, Du L. Epigenetic modulation in the initiation and progression of pulmonary hypertension. Hypertension 2019;74:733-9.

15. Napoli C, Benincasa G, Loscalzo J. Epigenetic inheritance 
underlying pulmonary arterial hypertension. Arterioscler Thromb Vasc Biol 2019;39:653-64.

16. Erkoç, Sultan Balız. Eskişehir Mahmudiye'de erişkinlerde hipertansiyon insidansı ve risk faktörleri. Halk Sağlığı Anabilim Dalı, Tıpta Uzmanlık Tezi, Eskişehir, 2013.

17. Watanabe K, Narumi T, Watanabe T, Otaki Y, Takahashi T, Aono $\mathrm{T}$, et al. The association between microRNA-21 and hypertension-induced cardiac remodeling. PLoS One 2020;15:e0226053.

18. Miao R, Wang Y, Wan J, Leng D, Gong J, Li J, et al. Microarray analysis and detection of microRNAs associated with chronic thrombo embolic pulmonary hypertension. BioMed Res Int 2017;2017:8529796.

19. Nosalski R, Siedlinski M, Denby L, McGinnigle E, Nowak M, Cat AND, et al. T-cell-derived miRNA-214 mediates perivascular fibrosis in hypertension. Circ Res 2020;126:988-1003.

20. Qi H, Liu Z, Liu B, Cao H, Sun W, Yan Y, et al. micro-RNA screening and prediction model construction for diagnosis of saltsensitive essential hypertension. Medicine (Baltimore) 2017;96:e6417.

21. Nandakumar P, Tin A, Grove ML, Ma J, Boerwinkle E, Coresh J, et al. MicroRNAs in the miR-17 and miR-15 families are downregulated in chronic kidney disease with hypertension. PLoS One 2017;12:e0176734.

22. Dluzen DF, Kim Y, Bastian P, Zhang Y, Lehrmann E, Becker $\mathrm{KG}$ et al. MicroRNAs modulate oxidative stress in hypertension through PARP-1 regulation. Oxid Med Cell Longev 2017;2017:3984280.

23. Liu A, Liu Y, Li B, Yang M, Liu Y, Su J. Role of miR-223-3p in pulmonary arterial hypertension via targeting ITGB3 in the ECM pathway. Cell Prolif 2019;52:e12550.

24. Mondejar-Parreno G, Callejo M, Barreira B, Morales-Cano D, Esquivel-Ruiz S, Moreno L, et al. miR-1 is increased in pulmonary hypertension and downregulates Kv1.5 channels in rat pulmonary arteries. J Physiol 2019;597:1185-97.
25. Yavuzer H, Ali C, Yeşilova A, Cengi M, Yavuzer S, Yaldıran AL. [The investigation of MiR-125a and MiR-155 levels in white coat hypertension and essential hypertension]. Okmeydanı Tip Dergisi 2017 33:261-9. [Article in Turkish]

26. Klimczak D, Kuch M, Pilecki T, Żochowska D, Wirkowska A, Pączek L. Plasma microRNA-155-5p is increased among patients with chronic kidney disease and nocturnal hypertension. $\mathrm{J}$ Am Soc Hypertens. 2017;11:831-41.e4.

27. Zeng J, Lei J, Wei Y, Zheng Z, Zhang W, Fu Y, et al. Molecular mechanisms in microRNA-mediated TRB3 gene and hypertension left ventricular hypertrophy. Exp Ther Med 2017;13:1907-11.

28. Li F, Shi W, Wan Y, Wang Q, Feng W, Yan X. Prediction of target genes for miR-140-5p in pulmonary arterial hypertension using bioinformatics methods. FEBS Open Bio 2017;7:1880-90. 29. Zhang X, Wang X, Wu J, Peng J, Deng X, Shen Y, et al. The diagnostic values of circulating miRNAs for hypertension and bioinformatics analysis. Biosci Rep 2018;38:BSR20180525.

30. Biró O, Alasztics B, Molvarec A, Joó J, Nagy B, Rigó J Jr. Various levels of circulating exosomal total-miRNA and miR210 hypoxamiR in different forms of pregnancy hypertension. Pregnancy Hypertens 2017;10:207-12.

31. Li Q, Qian Z, Wang L. Pri-microRNA-124 rs531564 polymorphism minor allele increases the risk of pulmonary artery hypertension by abnormally enhancing proliferation of pulmonary artery smooth muscle cells. Int J Chron Obstruct Pulmon Dis 2017;12:1351-61.

32. Zeng Z, Yao J, Li Y, Xue Y, Zou Y, Shu Z, et al. Anti-apoptosis endothelial cell-secreted microRNA-195-5p promotes pulmonary arterial smooth muscle cell proliferation and migration in pulmonary arterial hypertension. J Cell Biochem 2018;119:2144-55. 33. Li Y, Ren W, Wang X, Yu X, Cui L, Li X, et al. MicroRNA150 relieves vascular remodeling and fibrosis in hypoxia-induced pulmonary hypertension. Biomed Pharmacother 2019;109:17409. 